\title{
Phosphoserine aminotransferase deficiency
}

INSERM

\section{Source}

INSERM. (1999). Orphanet: an online rare disease and orphan drug data base.

Phosphoserine aminotransferase deficiency. ORPHA:284417

Phosphoserine aminotransferase deficiency is an extremely rare form of serine deficiency syndrome (see this term) characterized clinically in the two reported cases to date by acquired microcephaly, psychomotor retardation, intractable seizures and hypertonia. 